\title{
Clinical-pathological characteristics of patients treated for cancers of the eyelid skin and periocular areas
}

\author{
Robert Brodowski, ${ }^{1, A-D}$, Paweł Pakla ${ }^{1, B, C}$, Mateusz Dymek ${ }^{1, C}$, Małgorzata Migut 1,B, \\ Miłosz Ambicki ${ }^{1, B}$, Wojciech Stopyra ${ }^{1, C}$, Dorota Ozga ${ }^{2, B}$, Bogumił Lewandowski ${ }^{1, A, E, F}$ \\ ${ }^{1}$ Department of Maxillofacial Surgery, Frederic Chopin Clinical Hospital No. 1 in Rzeszów, Poland \\ ${ }^{2}$ Department of Emergency Medicine, Faculty of Medicine, University of Rzeszów, Poland \\ A - research concept and design; $\mathrm{B}$ - collection and/or assembly of data; $\mathrm{C}$ - data analysis and interpretation; \\ $\mathrm{D}$ - writing the article; $\mathrm{E}$ - critical revision of the article; $\mathrm{F}$ - final approval of the article
}

Address for correspondence

Robert Brodowski

E-mail: robert.brodowski@wp.pl

Funding sources

None declared

Conflict of interest

None declared

Acknowledgements

We would like to thank Dr. David Aebisher for linguistic editing.

Received on May 26, 2017

Reviewed on July 18, 2017

Accepted on September 26, 2017

Published online on 0ctober 2, 2018

Cite as

Brodowski R, Pakla P, Dymek M, et al. Clinical-pathological characteristics of patients treated for cancers of the eyelid skin and periocular areas. Adv Clin Exp Med. 2019;28(3): 325-330. doi:10.17219/acem/78023

DOI

10.17219/acem/78023

Copyright

Copyright by Author(s)

This is an article distributed under the terms of the

Creative Commons Attribution Non-Commercial License

(http://creativecommons.org/licenses/by-nc-nd/4.0/)

\section{Abstract}

Background. Malignant cancers of the eyelid skin and the periocular area comprise 5-10\% of facial skin malignant cancers. Basal cell carcinomas (BCCS) dominate, comprising approx. 80-90\% of cancers of this area of the face. Considerably less often, in 9-14\% of cases, squamous cell carcinomas (SCCS) are observed.

Objectives. The aim of this study is to provide an epidemiological-clinical assessment of patients treated over the period 2006-2015 for primary malignant cancers of the eyelid skin considering histological diagnosis and clinical staging.

Material and methods. This study was based on an analysis of the medical records of 262 patients. Demographic data, age, sex, size and location of lesions, histological types, and clinical staging were assessed.

Results. In the analyzed group of 262 patients, most were over the age of 60 years. Primary cancers were most frequently located in the area of the medial canthus of the eye and in the lower eyelid skin. They were mainly lesions of $6-10 \mathrm{~mm}$ and $16-20 \mathrm{~mm}$ with histologically diagnosed basal cell carcinoma of nodular and cystic types.

Conclusions. The most represented group was that of patients aged 60-70 years with primary cancers located in the medial canthus of the eye (47.3\%) and in the lower eyelid. Basal cell carcinoma was diagnosed, mainly nodular and cystic types.

Key words: skin, malignant tumor, eyelid, epidemiological studies 
Eyelids constitute a facial aesthetic unit that has a complex anatomical structure which, apart from the function of protecting the eyeball, is of high importance for expressing emotions, feelings and moods. Accordingly, the diagnostics and treatment of cancers located in this part of the face cause difficulties in surgical practice. Epidemiological data shows that $5-10 \%$ of malignant cancers of the facial skin affect eyelids and the periocular area. ${ }^{1-4}$

Environmental factors, among others, play a significant role in the etiopathogenesis of malignant skin cancers of the periocular tissues and face. Facial skin, including the periocular area, as an exposed part of body, is vulnerable to the intense effects of UVB radiation, mainly from sunlight. Other factors predisposing to facial skin cancer development are potentially malignant lesions, i.e., actinic keratosis, sunburn and pigment changes. ${ }^{5-8}$

Among the histological types of malignant eyelid cancers, the most common is basal cell carcinoma (BCC), which comprises approx. $80-90 \%$ of all cancers of this area of the face. Considerably less often, in 9-14\% of cases, squamous cell carcinoma (SCC) is observed. Adenocarcinomas are least often diagnosed. ${ }^{9-12}$

\section{Objectives}

The aim of this study was to provide an epidemiologicalclinical assessment of patients treated at the Department of Maxillofacial Surgery of the Frederic Chopin Clinical Regional Hospital in Rzeszów, Poland, over the period 2006-2015 for primary malignant cancers of the eyelid skin. Moreover, the study was aimed at histological diagnosis and the clinical staging of particular cancer types located in the periocular area.

\section{Material and methods}

This study was based on an analysis of the medical records of 262 patients treated at the Department of Maxillofacial Surgery of the Frederic Chopin Clinical Regional Hospital in Rzeszów over the period 2006-2015 for primary malignant cancers of the eyelid skin and periocular tissues. Demographic data, age, sex, size and location of lesions, histological types, and clinical staging were assessed. The collected data was subjected to statistical analysis using STATISTICA v. 10.0 system (StatSoft Inc., Tulsa, USA). Two tests were used for the analysis: Pearson's $X^{2}$ test, which assessed variable dependence in which the qualitative (not quantitative) data was taken into consideration, and the unilateral structure indicators significance test, which was used for comparing the amount and the percentage of a given option in order to determine if any of the indicated options occurs considerably more often than the others. The tests used in the analysis were nonparametric. Statistical significance was taken as $\mathrm{p}<0.05$.

\section{Results}

The results obtained from the conducted test material assessment are presented in the form of tables and descriptions. Between 2006 and 2015, a total of 2,062 patients were hospitalized at the department and treated on an outpatient basis for malignant head and neck skin cancers. This study solely concerns the 262 patients operated on due to malignant cancers of the eyelid skin and the periocular area on an inpatient basis, which constituted $12.7 \%$ of the total number of patients treated for malignant head and neck skin cancers. Table 1 shows the number of patients treated during particular years for skin cancers located in the periorbital area and demonstrates that in the last decade, annually 20-30 patients were treated for cancer located in this area. A slight increase in the number of patients with eyelid skin and periocular area cancer occurred year by year, yet at that time, this was not statistically significant $\mathrm{p}<0.05$.

Among the patients, there were 139 (53\%) women and $123(47 \%)$ men in the 11-94 age group. Data concerning the patients' sex and age is presented in Table 2.

In the analyzed material, the majority, i.e., $62.9 \%$ of patients are over 60 years of age. Among the patients, there were 6 people $(2.3 \%)$ under the age of 30 who were admitted to the hospital in order to excise minor skin lesions

Table 1. Number of patients treated for malignant cancers between 2006 and 2015

\begin{tabular}{|c|c|c|c|c|c|c|c|c|c|c|c|}
\hline Year & 2006 & 2007 & 2008 & 2009 & 2010 & 2011 & 2012 & 2013 & 2014 & 2015 & Total \\
\hline Number (\%) & $20(7.6)$ & $28(10.7)$ & $19(7.2)$ & $30(11.4)$ & $32(12.2)$ & $23(8.8)$ & $26(9.9)$ & $22(8.4)$ & $30(11.4)$ & $32(12.2)$ & $262(100.0)$ \\
\hline
\end{tabular}

Table 2. Sex and age of the treated patients

\begin{tabular}{|c|c|c|c|c|c|c|c|c|}
\hline \multirow{2}{*}{ Sex } & \multicolumn{8}{|c|}{ Age [years] } \\
\hline & $<30$ & $31-40$ & $41-50$ & $51-60$ & $61-70$ & $71-80$ & $\geq 81$ & Total \\
\hline Female; n (\%) & $3(2.2)$ & $3(2.2)$ & $16(11.5)$ & $32(23.0)$ & $31(22.3)$ & $28(20.1)$ & $26(18.7)$ & 139 \\
\hline Male; n (\%) & $3(2.4)$ & $1(0.8)$ & $13(10.6)$ & $26(21.1)$ & $26(21.1)$ & $34(27.6)$ & $20(16.3)$ & 123 \\
\hline Total; n (\%) & $6(2.3)$ & $4(1.5)$ & $29(11.1)$ & $58(22.1)$ & $57(21.8)$ & $62(23.7)$ & $46(17.6)$ & 262 \\
\hline$p$-value & \multicolumn{8}{|c|}{$x^{2}(6)=2.77 ; p=0.8376$} \\
\hline
\end{tabular}


$(<5 \mathrm{~mm})$ of the benign lump type in cases where histopathological examination of the material suggested the presence of basal cell carcinoma. Over time, an increase in the number of patients with eyelid skin cancer was observed. The statistical analysis of the material did not confirm a statistically significant relationship between the increase in the number of patients treated in particular 10-year age brackets and their sex. The difference between the number of patients in subsequent age brackets and the previous age bracket was statistically insignificant. Patients were referred for surgical treatment mostly by dermatologists, ophthalmologists, oncologists, general practitioners, and maxillofacial surgeons.

Patients admitted to the Clinic did not report any complaints, including pain, in most cases. The reason for being referred for treatment were mostly non-healing skin ulcerations and periocular tissue wounds, visual impairment caused by a growing tumor mass obscuring the field of vision, bleeding, and, rarely, aesthetic reasons.

In the case of 124 patients, who constituted $47.3 \%$ of patients, primary cancers were located in the area of the medial canthus of the eye, while in the case of 83 patients (31.7\%) they concerned the lower eyelid. In 26 patients (9.9\%), it was the upper eyelid, while in 29 patients (11.1\%), lesions were located in the area of the lateral canthus of the eye.

The statistical analysis of the data shows that the occurrence of cancers in the area of the medial canthus of the eye was considerably more frequent than in the remaining areas, which was statistically confirmed $(\mathrm{p}<0.05)$.

The sizes of lesions in several cases varied between less than $5 \mathrm{~mm}$, found in 22 patients (8.4\%), to more than $20 \mathrm{~mm}$. Cancers ranging in size between 6 and $10 \mathrm{~mm}$ were treated most often (in 113 patients; 43.1\%). Lesions between 11 and $15 \mathrm{~mm}$ were present in 40 patients (15.3\%), whereas those between 16 and $20 \mathrm{~mm}$ occurred in 67 cases (25.5\%). Lesions larger than $20 \mathrm{~mm}$ which spread into the surrounding tissues were found in 7 patients $(2.8 \%)$. The statistical analysis shows that the differences in the frequency of eyelid primary cancers between 6 and $10 \mathrm{~mm}$ in size were statistically significant $(\mathrm{p}<0.05)$ in comparison with the remaining eyelid and periocular area cancerous lesion sizes.

On the basis of clinical examination and histopathological verification, $\mathrm{BCCs}$ were observed most frequently, namely, in 213 patients (81.4\%), while SCCs were found in 38 patients (14.5\%). In 8 cases, i.e., 3.0\%, eyelid adenocarcinomas were present, whereas 3 patients (1.1\%) were diagnosed with eyelid skin malignant melanomas. The occurrence of $\mathrm{BCC}$ cancer was 4 times higher than the remaining types of malignant periocular area skin cancers.

An assessment of the patients with regard to the relationship between the type of malignant cancer and its location was conducted. Basal cell carcinomas were most frequently located in the medial canthus of the eye (in 102 patients; $47.9 \%$ ), while in 68 cases (31.9\%), it was found in the lower eyelid. The outbreak of BCCs in the upper eyelid affected 23 patients $(10.8 \%)$, while 20 patients $(9.4 \%)$ had it in the lateral canthus of the eye. Squamos cell carcinomas were also most often located in the medial canthus of the eye (in 17 patients; $44.7 \%$ ), while in 11 patients (28.9\%), it was located in the lower eyelid. Table 3 presents data regarding the relationship between the type of malignant cancer and its location with respect to the histopathological diagnosis, which shows that both BCCs and SCCs were mostly located in the medial canthus of the eye and concerned the lower eyelid.

The statistical analysis of the data regarding location shows that there are no statistically significant differences between the type of malignant cancer confirmed by histopathological examination and its location in periocular tissues $(\mathrm{p}=0.6134)$.

Over the period 2006-2015, a total of 213 patients were treated at the clinic for different types and forms of eyelid and periocular area BCC. Data regarding the particular forms of $\mathrm{BCC}$ is presented in Table 4.

Table 3. Location and histopathological type of malignant cancer

\begin{tabular}{|l|c|c|c|c|c|}
\multicolumn{1}{|c|}{ Location } & SCCs & BCCs & Adenocarcinoma & Melanoma malignum & Total \\
\hline Lower eyelid; $n(\%)$ & $11(28.9)$ & $68(31.9)$ & $2(25.0)$ & $2(66.7)$ & $83(31.7)$ \\
\hline Upper eyelid; $n(\%)$ & $2(5.3)$ & $23(10.8)$ & $1(12.5)$ & 0 & $26(9.9)$ \\
\hline Medial canthus; $n(\%)$ & $17(44.7)$ & $102(47.9)$ & $4(50)$ & $1(33.1)$ & $124(47.3)$ \\
\hline Lateral canthus; $n(\%)$ & $8(21.1)$ & $20(9.4)$ & $1(12.5)$ & 0 & $29(11.1)$ \\
\hline Total; $\boldsymbol{n}(\%)$ & $38(100)$ & $213(100)$ & $8(100)$ & $3(100)$ & $262(100)$ \\
\hline$p$-value & & & $X^{2}(9)=7.23 ; p=0.6134$ & & \\
\hline
\end{tabular}

SCCs - squamous cell carcinomas; BCCs - basal cell carcinomas.

Table 4. Occurrence of particular BCC forms in the group of treated patients

\begin{tabular}{|c|c|c|c|c|c|}
\multirow{2}{*}{\begin{tabular}{c} 
Number \\
\cline { 2 - 5 }
\end{tabular}} & nodular & ulcerative & cystic & cicatricial \\
\cline { 2 - 6 } & $90(42.2 \%)$ & $21(9.8 \%)$ & $81(38.0 \%)$ & $13(6.1 \%)$ & pigmented \\
\hline
\end{tabular}

BCCs - basal cell carcinomas. 
Table 5. Type of BCCs depending on location

\begin{tabular}{|c|c|c|c|c|c|}
\hline \multirow[b]{2}{*}{ Location } & \multicolumn{5}{|c|}{ Morphological types of BCCs } \\
\hline & $\begin{array}{c}\text { nodular } \\
\text { n (\%) }\end{array}$ & $\begin{array}{c}\text { ulcerative } \\
\mathrm{n}(\%)\end{array}$ & $\begin{array}{l}\text { cystic } \\
\text { n (\%) }\end{array}$ & $\begin{array}{c}\text { cicatricial } \\
\mathrm{n}(\%)\end{array}$ & $\begin{array}{c}\text { pigmented } \\
\mathrm{n}(\%)\end{array}$ \\
\hline Lower eyelid & $23(33.8)$ & $18(26.5)$ & $18(26.5)$ & $7(10.3)$ & $2(2.9)$ \\
\hline Upper eyelid & $11(47.8)$ & $3(13.0)$ & $7(30.4)$ & $2(8.7)$ & 0 \\
\hline Medial canthus & $51(50)$ & 0 & $46(45.1)$ & $3(2.9)$ & $2(2.0)$ \\
\hline Lateral canthus & $5(25.0)$ & 0 & $10(50.0)$ & $1(5.0)$ & $4(20.0)$ \\
\hline Total & $90(42.3)$ & $21(9.9)$ & $81(38.0)$ & $13(6.1)$ & $8(3.8)$ \\
\hline$p$-value & \multicolumn{5}{|c|}{$x^{2}(12)=60.13 ; p=0.0000$} \\
\hline
\end{tabular}

BCCs - basal cell carcinomas.

Most often, in a total of 90 patients (42.2\%), the nodular form of BCC was diagnosed, while there were 81 cases (38.0\%) with the cystic form of BCC. The pigmented form of BCC found in $3.9 \%$ of patients was the least frequently represented. The primary cancers of BCC in an ulcerative form were present in 21 patients $(9.8 \%)$, while 13 patients (6.1\%) suffered from the cicatricial type of BCC. The frequency of occurrence of the nodular and cystic forms in the analyzed material was similar. There were no statistically significant differences between the occurrence of these 2 forms ( $p=0.2880)$. The nodular and cystic forms occurred statistically more frequently than the remaining variants of $\mathrm{BCC}$. With respect to the further ulcerative form, in terms of occurrence, the difference was statistically significant for both the nodular type $(\mathrm{p}=0.0027)$ and the cystic type $(\mathrm{p}=0.0069)$. The statistical analysis shows that the nodular and cystic forms of BCC occurred considerably more frequently in the periocular area than did the remaining variants of $\mathrm{BCC}$.

A detailed assessment of the particular morphological forms of $\mathrm{BCC}$ shows that the lower eyelid was the location of mainly nodular and cystic lesions which, together with the cicatricial forms, accounted for more than $80 \%$ of cases. The lesions located in the upper eyelid were the most common nodular variations (in $47.8 \%$ of cases). In the medial canthus of the eye area, the nodular form also occurred most frequently (in 51 patients), while the cystic form was diagnosed in 46 patients $(45.1 \%)$. The cicatricial and the pigmented forms were mostly located in the lateral canthus area of the eye. The material presented indicates that the differences in the occurrence of the types and forms of BCC cancer were significantly related to their location $(\mathrm{p}=0.0000)$. The abovementioned data is presented in Table 5 .

Over the period 2006-2015, 38 patients with SCCs of the periocular area skin were treated. The degree of histo-

Table 6. Broder's eyelid SCC differentiation stages

\begin{tabular}{|l|c|c|c|}
\multirow{2}{*}{ Number } & \multicolumn{3}{|c|}{ Differentiation stages of SCCs } \\
\cline { 2 - 4 } & $\mathrm{G}_{1}$ & $\mathrm{G}_{2}$ & $\mathrm{G}_{3}$ \\
\hline $38(100.0 \%)$ & $19(50.0 \%)$ & $13(34.2 \%)$ & $6(15.8 \%)$ \\
\hline $\mathrm{p}$-value & $\mathrm{pG}_{1}-\mathrm{G}_{2}>0.05 ; \mathrm{pG}_{1}-\mathrm{G}_{3}>0.05 ; \mathrm{pG}_{2}-\mathrm{G}_{3}>0.05$ \\
\hline
\end{tabular}

SCCs - squamous cell carcinomas. pathological differentiation according to the Broder's scale regarding the percentage of mature, differentiated cells and atypical cells is shown in Table 6. Most frequently, in 19 patients, forms of well-differentiated cancer cells (G1) were observed; 13 patients (34.9\%) were diagnosed with cancer of type G2 (moderately differentiated) and 6 patients $(15.8 \%)$ had a poorly differentiated type of cancer (G3). There were no anaplastic SCCs (type G4) in the discussed material.

The statistical analysis demonstrates that differences in the occurrence of particular stages of histologically mature SCCs located in the periocular area were not statistically significant $(\mathrm{p}>0.05)$.

On the basis of the simplified TNM classification (feature T), developed by the Union of International Cancer Control (UICC), the clinical staging of eyelid skin cancer was assessed. ${ }^{2}$ In the analyzed group, the most frequent were outbreaks of cancer in stage $\mathrm{T}_{2} \mathrm{M}_{0} \mathrm{~N}_{0}$ (43.1\%). Tumors in stage $T_{3} M_{0} N_{0}$ were operated on in $40.8 \%$ of patients. Stage $\mathrm{T}_{1} \mathrm{M}_{0} \mathrm{~N}_{0}$ was treated in 35 patients (13.3\%). The analysis confirmed that the differences in the occurrence of eyelid skin cancers in clinical stages ranging from $\mathrm{T}_{1}$ and $\mathrm{T}_{2}, \mathrm{~T}_{1}$ and $\mathrm{T}_{3}, \mathrm{~T}_{1}$ and $\mathrm{T}_{4}, \mathrm{~T}_{2}$ and $\mathrm{T}_{4}, \mathrm{~T}_{3}$ and $\mathrm{T}_{4}$ were statistically significant. A detailed overview of the clinical staging of eyelid cancers is included in Table 7.

It seemed of interest whether there is a relationship between the clinical staging of malignant skin cancers (TNM) and their location in the periocular area. In the analyzed group of patients, the malignant cancers located in the medial canthus area of the eye were the most frequently operated on (in the cases of 124 patients [47.3\%]). They were mostly in the $\mathrm{T}_{3}$ and $\mathrm{T}_{4}$ clinical stages. In this location, there were also 3 patients in the $\mathrm{T}_{4}$ stage who required a wide-margin excision of tissues surrounding the cancer. Detailed data regarding the relationship between

Table 7. Clinical staging of eyelid cancers according to the TNM classification

\begin{tabular}{|c|c|c|c|c|}
\hline Number & $\mathrm{T}_{1} \mathrm{~N}_{0} \mathrm{M}_{0}$ & $\mathrm{~T}_{2} \mathrm{M}_{0} \mathrm{~N}_{0}$ & $\mathrm{~T}_{3} \mathrm{M}_{0} \mathrm{~N}_{0}$ & $\mathrm{~T}_{4} \mathrm{M}_{0} \mathrm{~N}_{0}$ \\
\hline 262 (100\%) & 35 (13.3\%) & $113(43.1 \%)$ & 107 (40.8\%) & $7(2.8 \%)$ \\
\hline p-value & \multicolumn{4}{|c|}{$\begin{array}{c}\mathrm{pT}_{1}-\mathrm{T}_{2}<0.05 ; \mathrm{pT}_{1}-\mathrm{T}_{3}<0.05 ; \mathrm{pT}_{1}-\mathrm{T}_{4}<0.05 ; \mathrm{pT}_{2}-\mathrm{T}_{4}<0.05 ; \\
\mathrm{pT}_{3}-\mathrm{T}_{4}<0.05 ; \mathrm{pT}_{2}-\mathrm{T}_{3}>0.05 \%\end{array}$} \\
\hline
\end{tabular}


Table 8. Clinical stage depending on primary outbreak location

\begin{tabular}{|c|c|c|c|c|c|}
\hline \multirow{2}{*}{ Location } & \multicolumn{5}{|c|}{ Clinical stage according to feature $\mathrm{T}$} \\
\hline & $\mathrm{T}_{1}$ & $\mathrm{~T}_{2}$ & $\mathrm{~T}_{3}$ & $\mathrm{~T}_{4}$ & total \\
\hline Medial canthus; n (\%) & $10(28.6)$ & $52(46.1)$ & $59(55.3)$ & $3(42.8)$ & $124(47.3)$ \\
\hline Lateral canthus; n (\%) & 0 & $17(15.1)$ & $11(10.2)$ & $1(14.3)$ & $29(11.1)$ \\
\hline Lower eyelid; n (\%) & $9(25.7)$ & $35(31.0)$ & $37(34.5)$ & $2(28.6)$ & $83(31.7)$ \\
\hline Upper eyelid; n (\%) & $16(45.7)$ & $9(7.8)$ & 0 & $1(14.3)$ & $26(9.9)$ \\
\hline Total; n (\%) & $35(100.0)$ & $113(100.0)$ & $107(100.0)$ & $7(100.0)$ & $262(100.0)$ \\
\hline$p$-value & \multicolumn{5}{|c|}{$(p>0.05)$} \\
\hline
\end{tabular}

the clinical staging and the location of the cancers is shown in Table 8.

The differences in the occurrence of the particular clinical stages of cancers and their location were not statistically significant $(\mathrm{p}>0.05)$.

\section{Discussion}

In the analyzed group of patients operated on at the Department of Maxillofacial Surgery of the Frederic Chopin Clinical Regional Hospital in Rzeszów, the dominant group were patients aged over 60 years, which is in accordance with the epidemiological data published by other authors and regarding not only primary cancers, but also the recurrence of facial skin malignant cancers. ${ }^{13,14}$

The most frequently histologically diagnosed eyelid skin cancer in the examined group was BCC, which occurred in $81.4 \%$ of patients. A similar frequency of occurrence was noted by Spiteri and McCormick, as well as Allali et al.,15 Among the excised BCCs, the most often diagnosed form were the nodular and cystic variations, which were found in $38.0 \%$ of patients. This was confirmed by statistical analysis. Similar results were obtained by Ben Simon et al., ${ }^{8,14}$

The nodular and cystic types of BCC occurred considerably more often in the medial canthus area of the eye in comparison to the remaining periocular areas. The location was the medial canthus of the eye in the examined group in $47.3 \%$ of the overall number of periocular area tumors operated on. The results of these examinations are compliant with the observations published by Ilijn et al. $6,10,13$

An analysis of our own material shows that the largest group were the cancers with diameters ranging from 10 to $20 \mathrm{~mm}$ and classified as $T_{2}$ or $T_{3}$ according to the UICC classification. This may result from the characteristics of the patients who qualified for surgical treatment at the Department. They were patients aged over 60 years, mostly afflicted with ailments and diseases of other systems. Minor lesions are mostly operated on at dermatological, laryngological and general surgery clinics. Histopathological verification of the excised eyelid tumors allowed for a diagnosis of SCC in 38 patients (14.5\%) with dominant, well-differentiated $\mathrm{G}_{1}$ cancer constituting $50 \%$ of histological diagnoses. There was no statistically significant correlation between the clinical stage of the SCC and the location of the tumor. The results obtained from these observations correspond with the publication published by Nemet's and Donaldson's teams. ${ }^{9,10}$ On the basis of the retrospectively studied characteristics of the treated patients, the following conclusions are presented.

\section{Conclusions}

Between 2006 and 2015, 262 patients were treated for periocular area skin cancers at the Department of Maxillofacial Surgery of the Frederic Chopin Clinical Regional Hospital in Rzeszów. They represent $12.7 \%$ of all patients hospitalized due to head and neck skin cancers at that time.

The most represented group (45.3\%) was that of patients aged between 60 and 70 years.

Primary cancers were mostly located in the medial canthus of the eye (47.3\%) and in the lower eyelid (31.7\%).

In $81.4 \%$ of treated patients, BCCs of mainly nodular and cystic types were diagnosed, while $14.5 \%$ of patients had SCCs.

The majority of the treated patients were diagnosed with cancer outbreaks in the $\mathrm{T}_{3}(16-20 \mathrm{~mm})$ and $\mathrm{T}_{2}(6-10 \mathrm{~mm})$ clinical stages.

\section{References}

1. Spiteri N, McCormick A. Periocular basal cell carcinoma. OiP. 2013;14: 97-106.

2. Wang $\mathrm{CJ}$, Zhang $\mathrm{HN}, \mathrm{Wu} \mathrm{H}$, et al. Clinicopathologic features and prognostic factors of malignant eyelid tumors. Int J Ophthalmol. 2013;6(4):442-447.

3. Coroi MC, Roşca E, Muţiu G, Coroi T, Bonta M. Eyelid tumors: Histopathological and clinical study performed in County Hospital of Oradea between 2000-2007. Rom J Morphol Embryol. 2010;51(1):111-115.

4. Cook BE, Bartley GB. Treatment options and future prospects for the management of eyelid malignancies. Ophthalmology. 2001;108(11): 2089-2098.

5. Cook BE Jr, Bartley GB. Epidemiologic characteristics and clinical course of patients with malignant eyelid tumors in an incidence cohort in Olmsted County, Minnesota. Ophthalmology. 1999:106(4): 746-750.

6. Esmaeli B, Wang B, Deavers $M$, et al. Prognostic factors for survival in malignant melanoma of the eyelid skin. Ophthalmic Plast Reconstr Surg. 2000;16(4):250-257.

7. Hamada S, Kersey T, Thaller VT. Eyelid basal cell carcinoma: Non-Mohs excision, repair and outcome. Br J Ophthalmol. 2005;89(8):992-994. 
8. Kale SM, Patil SB, Khare N, et al. Clinicopathological analysis of eyelid malignancies: A review of 85 cases. Indian J Plast Surg. 2012;45(1): 22-28.

9. Nemet AY, Deckel Y, Martin PA, et al. Management of periocular basal and squamous cell carcinoma: A series of 485 cases. Am J Ophthalmol. 2006;142(2):293-297.

10. Donaldson MJ, Sullivan TJ, Whitehead KJ, Williamson RM. Squamous cell carcinoma of the eyelids. Br J Ophthalmol. 2002;86(10):1161-1165.

11. Vaziri M, Buffam FV, Martinka M, Oryschak A, Dhaliwal H, White VA. Clinicopathologic features and behavior of cutaneous eyelid melanoma. Ophthalmology. 2002; 109(5):901-908.
12. Burns SJ, Foss AJ, Butler TK. Outcome of periocular sebaceous gland carcinoma. Ophthalmic Plast Reconstr Surg. 2005:21(5):353-355.

13. Iljin A, Zieliński T, Antoszewski B, Sporny S. Clinicopathological analysis of reccurent basal cell carcinoma of the eyelid. Postepy Dermatol Alergol. 2016;33(1):42-46.

14. Ben Simon GJ, Lukovetsky S, Lavinsky F, Rosen N, Rosner M. Histological and clinical features of primary and recurrent periocular basal cell carcinoma. ISRN Ophthalmology. 2012:354829.

15. Allali J, D'Hermies FD, Renard G. Basal cell carcinomas of the eyelids. Ophthalmologica. 2005;219(2):57-71. 